Anuario de Historia Regional y de las Fronteras, Vol. 23 No. 1 DOI: http://dx.doi.org/10.18273/revanu.v23n1-2018007 (c) (i)

\title{
Mujeres detrás de la escena: Isabel Carrasquilla y Sofía Ospina de Navarro, dramaturgas al margen en la primera mitad del siglo XX en Colombia*
}

\begin{abstract}
Resumen
El artículo analiza las representaciones de género de tres comedias de Isabel Carrasquilla de Arango y dos de Sofía Ospina de Navarro, quienes son consideradas como intelectuales; productoras de representaciones y de discursos. Aunque su destacada posición social les permitió intervenir en la escena pública de Medellín, dominada por esquemas masculinos, en parte como un legado de ese poder letrado del siglo XIX, estuvieron al margen, pues no contaron con educación superior y, dentro de la escena cultural, su actividad intelectual se asoció generalmente a las figuras masculinas que las rodearon durante sus vidas. Así mismo, sus producciones fueron identificadas con los denominados géneros menores: crónica, cuento y pequeñas obras teatrales, que se consideraban aceptables y propicias para las mujeres. Sin embargo, sus comedias presentan una visión renovada, y a veces transgredida, sobre los estereotipos de género de la época.
\end{abstract}

Palabras clave: comedia, dramaturgo, intelectual, género, historia cultural.

Referencia para citar este artículo: CORREA SERNA, Nancy Yohana (2018). Mujeres detrás de la escena: Isabel Carrasquilla y Sofía Ospina de Navarro, dramaturgas al margen en la primera mitad del siglo XX en Colombia. En Anuario de Historia Regional y de las Fronteras. 23 (1). pp. 173-196.

Fecha de recepción: 15/09/2017

Fecha de aceptación: 27/11/2017

Nancy Yohana Correa Serna: Estudiante del Doctorado en Historia de la Universidad Nacional de Colombia Sede Medellín, Colombia. Historiadora, Magíster en Historia de la Universidad Nacional de Colombia Sede Medellín, Colombia. Grupo de investigación: Historia, Espacio y Cultura. Código ORCID: https://orcid.org/0000-0001-6757-6029. Correo electrónico: nycorreas@unal.edu.co.

\footnotetext{
*El artículo hace parte de la tesis del Doctorado en Historia titulada De las tablas al estudio de grabación. Mujeres en escena en Colombia, 1897-1954, la cual se encuentra en proceso de elaboración y es asesorada por el Doctor Álvaro Andrés Villegas Vélez. Una primera versión del texto fue presentada en el III Congreso de Historia Intelectual de América Latina, llevado a cabo en el Colegio de México en octubre del 2016.
} 


\title{
Women Behind the Scenes: Isabel Carrasquilla and Sofía Ospina de Navarro, Dramatists on the Sideline in the First Half of the 20th Century in Colombia
}

\begin{abstract}
The article analyzes the gender representations of three comedies of Isabel Carrasquilla de Arango and two of Sofia Ospina de Navarro, who are considered as intellectuals; producers of representations and speeches. Although their prominent social position allowed them to intervene in the public scene of Medellin, dominated by male schemes, partly as a legacy of that literate power of the nineteenth century, they were on the margins as they did not have a higher education and, within the cultural scene, their intellectual activity was generally associated with the male figures who surrounded them during their lives. Also, their productions were identified with the so-called minor genres: chronicle, short story and small theatrical works, which were considered acceptable and propitious for women. However, their comedies present a renewed and sometimes transgressed vision of the gender stereotypes of the time.
\end{abstract}

Keywords: Comedy, Playwright, Intellectual, Gender, Cultural History.

\section{Mulheres atrás da cena: Isabel Carrasquilla e Sofia Ospina de Navarro, dramaturgas à margem na primeira metade do século XX na Colômbia}

\section{Resumo}

O artigo analisa as representações de gênero de três comédias de Isabel Carrasquilla de Arango e duas de Sofía Ospina Navarro, que são consideradas intelectuais; produtoras de representações e de discursos. Apesar de que sua posição social destacada lhes permitiu intervir no espaço público de Medellín, dominado por esquemas masculinos, em parte como um legado de este poder letrado do século $X I X$, elas estiveram à margem porque não tinham ensino superior e, dentro da cena cultural, sua atividade intelectual era geralmente associada a figuras masculinas que as circundavam durante suas vidas. Da mesma forma, suas produções foram identificadas com os chamados gêneros menores: crônicas, contos e pequenas obras teatrais, que se consideravam aceitáveis e propicias para as mulheres. No entanto, suas comédias apresentam uma visão renovada e a vezes transgressora sobre os estereótipos de gênero da época.

Palavras-Chave: Comédia, dramaturgo, intelectual, história cultural. 


\section{Introducción}

Ni realidad más allá de los bastidores

Ni realidad real en quien ve,

Sino solamente real el escenario y los actores

Reales como máscaras y no como la persona que cada uno es.

Fernando Pessoa

Dramaturgas al margen fueron dos mujeres que, en medio de la construcción de un campo intelectual en Medellín, centrado casi en su totalidad en figuras masculinas, escribieron y pusieron en la escena pública su comprensión sobre las transformaciones sociales que experimentó la ciudad en las primeras décadas del siglo XX. Si bien, su posición social les permitió figurar con cierta comodidad en el escenario cultural, las estructuras de dominación de género, instaladas en las relaciones tradicionales de los sexos, las situó en una posición en la cual, pese a las apariciones que ambas tuvieron en diferentes espacios de sociabilidad, el ámbito doméstico fue el más importante. Así que estuvieron al margen de los centros de poder político ${ }^{1}$, no contaron con educación superior, y dentro de la escena cultural local, su actividad intelectual en algunas ocasiones se asoció a las figuras masculinas que las rodearon durante sus vidas. Sin embargo, escribir desde las márgenes, les permitió ocupar "un espacio fronterizo entre los depósitos culturales que permitía nuevos crecimientos e híbridos"2; se convertían así, en una especie de intermediarias culturales que, a través de sus escritos, difundían ciertos modos de relación en la Medellín del nuevo siglo.

Las dos hicieron parte de la generación intermedia entre el siglo XIX y el siglo XX, Isabel Carrasquilla nació en Santo Domingo-Antioquia en 1865 y murió en Medellín en 1941, mientras que la vida de Sofía Ospina de Navarro transcurrió totalmente en Medellín entre 1892 y 1974. Si bien, la segunda vivió gran parte del siglo XX, ambas compartieron algunas afinidades electivas, entre ellas, la clase y el género, unas afinidades que se pueden comprender según Michael Löwy, como "[...] el proceso por el cual dos formas culturales entran, a partir de ciertas analogías significativas, en un parentesco íntimo o afinidad de sentido, en una relación de atracción e influencia recíproca, elección mutua, convergencia activa y reforzamiento mutuo"3. Ellas asistieron, por ejemplo, al Centro Femenino de Estudios de Medellín, hicieron parte de algunas de las tertulias literarias más conocidas de la ciudad y escribieron obras de teatro y crónicas. Además, fueron testigos y participantes activas de la transformación social local en la primera mitad del siglo XX, en una ciudad que presentó un

\footnotetext{
${ }^{1}$ Aunque Sofía Ospina sería concejala municipal en los últimos años de su vida.

${ }^{2}$ Zemon Davis, Natalie. Mujeres de los márgenes. Tres vidas del siglo XVII (Madrid: Ediciones Cátedra, 1999), p. 267.

${ }^{3}$ Löwy, Michael. "El concepto de afinidad electiva en Max Weber", en Aronson, Perla (ed.), La vigencia del pensamiento de Max Weber a cien años de "La ética protestante y el espiritu del capitalismo" (Buenos Aires: Gorla, 2007), p. 101.
} 
Mujeres detrás de la escena: Isabel Carrasquilla y Sofia Ospina de Navarro, dramaturgas...

crecimiento demográfico sin precedentes en el país, pues pasó de contar en 1905 con 54.946 habitantes, a tener 358.189 en $1951^{4}$.

El aumento de la población, que se debió en gran parte a la migración de campesinos a la ciudad para integrarse al proceso económico local, y que estuvo caracterizado por una incipiente industrialización, contribuyó a transformar las relaciones y las representaciones sociales que hasta principios del siglo XX circulaban en la ciudad. Así, lo que podemos llamar industria cultural, materializada en la literatura, el teatro, el cine y la radio, actuó como productora de nuevas ideas y sensibilidades; experiencias que convocaron a gran parte de la elite intelectual, en particular a la conservadora, a producir y a poner en circulación un sistema de relaciones sociales que, desde diferentes lugares, prolongaran las formas tradicionales de reconocerse y de legitimarse unos de otros 5 .

Aunque ninguna de las dos se autorreconoció como intelectual; ambas incidieron en la opinión pública y fueron productoras de representaciones y de discursos que circularon por medio de revistas, de periódicos y de diversos espacios para la representación escénica, fueron "[...] productoras y consumidoras sistemáticas de símbolos, creencias, concepciones del mundo, ideas, valores e imaginarios, $[\ldots \mathrm{y}$ ocuparon] un lugar intersticial, que cumplió funciones conectivas e intermediarias"6. Isabel Carrasquilla escribió sus primeras dos obras de teatro desde el anonimato y sus impresiones de viaje desde el lugar de una abuela que deseaba dejarles a sus nietos un testimonio de su paso por Panamá, Estados Unidos y algunos países de Europa. Ella se retiró al campo a escribir sus memorias, con el fin de tener la calma y la tranquilidad que precisaba para su creación, pues consideraba que eran "chocheras de vieja" y que por lo mismo debían "mirarse con sonrisa indulgente"7. Teresa Santamaría, fundadora y directora de la revista Letras y Encajes, afirmaría tras su muerte que, Carrasquilla, a medida que avanzaba en la escritura de su libro Recuerdos de viaje, dejaba los originales en la revista ${ }^{8}$, de los cuales vieron la luz siete crónicas autobiográficas de sus experiencias en el exterior. Para Santamaría, Carrasquilla había sido una notabilísima escritora, a quien “[...] quizá la tarea difícil de atender, como es debido, a la perfecta formación de su hogar y también que en los años de su juventud

\footnotetext{
${ }^{4}$ Ramírez Patiño, Sandra Patricia. "Cuando Antioquia se volvió Medellín, 1905-1950. Los perfiles de la inmigración pueblerina hacía Medellín”, en Anuario Colombiano de Historia Social y de la Cultura, vol. XXXVIII, núm. 2, Bogotá, Universidad Nacional de Colombia, 2011, p. 223.

${ }^{5}$ Para este momento el profesor Gilberto Loaiza habla de un declive del poder letrado, precisamente por la aparición de esos medios. Loaiza Cano, Gilberto. Poder Letrado: ensayos sobre historia intelectual de Colombia, siglos XIX y XX (Cali: Universidad del Valle, 2014).

${ }^{6}$ Loaiza Cano, Gilberto. "Entre la historia intelectual y la historia cultural, una ambigüedad fecunda", en Hering, Max (ed.), Historia Cultural desde Colombia. Categorias y debates (Bogotá: Universidad Nacional de Colombia, 2012), p. 347.

${ }^{7}$ Carrasquilla, Isabel. Impresiones de viaje (Medellín: EAFIT, 2011), p. 17. Así mismo llama la atención que en una obra de teatro que publicara en 1932, Pepa Escandón, invita a que dos de sus partes puedan ser suprimidas, el prólogo y el cierre. Carrasquilla, Isabel. Pepa Escandón (Medellín: Bedout, 1932), pp. 7 y 77. Esto podría observarse como una evocación a la autoría intervenida.

8 "Necrología: El maestro Tomas Carrasquilla, Doña Isabel Carrasquilla de Arango", en Letras y Encajes, núm. 174, Medellín, Tipografía Industrial, 1941, pp. 5053-5054.
} 
nuestras mujeres no escribían y ni era bien visto que lo hicieran, doña Isabel solo comenzó a escribir y a revelarse como buena escritora a avanzada edad. Su estilo era sencillo, ameno, muy narrativo" 9

Por su parte, Ospina de Navarro, no tenía una opinión muy disímil sobre su oficio, pues uno de sus libros de crónicas más difundidos lo tituló La abuela cuenta. Según la misma Ospina, en su proceso creativo se daba a escribir en "[...] la cama, en el comedor, en la sala, donde me coja la gana. Después ordeno, pulo, distribuyo, suprimo y agrego. Esa es mi manera. [...] Aprovechando la posición social que ocupo; observo y después reconstruyo. Mi labor es de crítica" ${ }^{\prime 10}$. Una de las razones por las que ambas no ubicaban su trabajo como un ejercicio académico e intelectual en la escena cultural local, tenía que ver con el valor asignado socialmente al mismo, el cual se asociaba con una afición de las escritoras, las cuales debían dedicarse al compromiso que habían adquirido cuando contrajeron matrimonio, cuidar del hogar y velar por las labores domésticas.

Pese a lo anterior, propio de las mujeres de la elite de su época, para quienes las relaciones y las costumbres familiares eran los aspectos más importantes de sus vidas y para quienes la educación que recibieron no trascendió a estudios superiores, ni tuvieron una enseñanza formal en la construcción de textos, el reconocimiento en el medio y en la opinión pública se manifestó con la legitimación de su trabajo por parte de algunos escritores y del público en general consumidor de sus obras. Uno de los escritores que no dudó en expresar su apoyo a Ospina de Navarro, fue Tomás Carrasquilla. Si bien, las dos fueron muy cercanas al escritor, pues Isabel, su hermana, vivió con él durante toda su vida, incluso después de contraer matrimonio, pues le había prometido a su madre hacerse cargo de él ${ }^{11}$, tuvo más complacencia por Ospina, quien era su amiga y a quien consideraba como la mejor cuentista de la época. Su admiración por la escritora la plasmó en una carta que envió a la Revista Letras y Encajes en 1926, en la cual destacaba sus dotes especiales para las labores literarias, las cuales, con un estilo sencillo y natural, fácilmente funcionarían para escribir novelas sobre los hogares de Medellín ${ }^{12}$. Para la investigadora Paloma Pérez Sastre: "No hay duda del papel generoso que jugó Tomás en el despertar literario de las mujeres en los años veinte; así como de la identificación de éstas con su credo estético que resaltaba lo sencillo, cotidiano y natural, y que literalmente abrió la puerta de la literatura para ellas en Antioquia"13.

\footnotetext{
9 Santamaría de González, Teresa. "Isabel Carrasquilla de Arango", en Letras y Encajes, núm. 175, Medellín, Tipografía Industrial, 1941, pp. 5117-5118.

10 "Doña Sofía Ospina de Navarro escribirá la biografía del maestro Carrasquilla", El Colombiano, Medellín, 13 de julio de 1943.

${ }^{11}$ Pérez Sastre, Paloma. "Edición comentada de las impresiones de viaje de una abuela para sus nietos de Isabel Carrasquilla de Arango", en Guardia, Sara Beatriz (ed.), Viajeras entre dos Mundos (Lima: Centro de Estudios la Mujer en la Historia de América Latina CEHMAL, 2011), p. 240.

${ }^{12}$ Carrasquilla, Tomas. "Concepto del maestro Carrasquilla”, en Letras y Encajes, núm. 3, Medellín, Tipografía Industrial, 1926, p. 36.

${ }^{13}$ Pérez Sastre, Paloma. Edición comentada de las impresiones de viaje..., p. 240.
} 
Mujeres detrás de la escena: Isabel Carrasquilla y Sofia Ospina de Navarro, dramaturgas...

En contraste, Tomás casi nunca estuvo de acuerdo con que su hermana Isabel escribiera. Por esa razón, Isabel encarnó para la publicación de su primera obra de teatro, el tipo de escritora que Graciela Batticuore denomina de autoría escondida, en la cual la autora omite su nombre en las ediciones y se camufla bajo la protección del anonimato o el pseudónimo ${ }^{14}$. En este sentido, afirma Pérez Sastre que Isabel ocultó su nombre bajo los pseudónimos de Equis y Zeta para la publicación de dos comedias basadas en la reconocida obra de Tomás Carrasquilla Frutos de mi tierra, y sin firmar solía mandar coplas al programa de radio de Abel Farina ${ }^{15}$.

Sin duda, el campo de la escritura fue un escenario vedado para casi todas las mujeres de la época y la dramaturgia aún más, pues implicaba la representación en escena, a una gran cantidad de público, de situaciones de la vida privada desde la óptica femenina ${ }^{16}$. Con todo, al final de su existencia, Isabel escribió sus impresiones de viaje, y, aunque en vida solo fueron publicados algunos apartes, el ejercicio intelectual de recopilar sus memorias, la ubica en lo que Batticuore llama como autoría póstuma. Las anteriores denominaciones las acuña la especialista a aquellas mujeres que transitaron entre la pasividad de ser lectoras y la creatividad que les implicó convertirse en escritoras, para lo cual, muchas de ellas, se vieron en la necesidad de acudir a diferentes tipos de autorías como un recurso de sobrevivencia en el campo intelectual, que se constituía como un sistema de líneas de fuerza, las cuales se oponían y se agregaban y se le confería una estructura $^{17}$. El campo intelectual de la ciudad de Medellín finalizando los años veinte e iniciando los treinta, época en que publicaron Ospina de Navarro y Carrasquilla de Arango gran parte de sus escritos, empezaba a constituirse y a dinamizarse con un nuevo agente, que había permanecido casi en su totalidad, ausente en esos primeros años del siglo XX. Así, las mujeres empezaron a publicar en algunas revistas, entre ellas Cyrano (1921-1923), que contó con la pluma de algunas mujeres liberales: Fita Uribe, María Cano, María Eatsman y Enriqueta Angulo. En la revista Sábado participaron 52 mujeres en un concurso de cuentos femenino y, la revista Letras y Encajes, inició labores en 1926. Lo anterior se explica por la circulación de nuevas ideas en el país; el socialismo empezaba a permear el movimiento obrero local y el feminismo posesionaba en la escena pública mundial, la necesidad de que las mujeres se convirtieran en ciudadanas y en sujetos de derecho. En este sentido, en las publicaciones liberales, las mujeres escribieron sobre temas que en la literatura local poco se habían tratado. Dicha situación encendió las alarmas de las autoridades, que, en el marco de la hegemonía conservadora, no vieron con buenas intenciones este tipo de opiniones que conversaban con lenguajes disimiles a los postulados de la doctrina conservadora y que hasta ahora se habían materializado en programas de gobierno excluyentes de las necesidades de las mujeres del país, entre ellas, las que empezaban a ser parte de la clase obrera.

\footnotetext{
${ }^{14}$ Batticuore, Graciela. La mujer romántica. Lectoras, autoras y escritores en la Argentina: 1830-1870 (Buenos Aires: Edhasa, 2005).

${ }^{15}$ Pérez Sastre, Paloma. Edición comentada de las impresiones de viaje..., p. 240.

${ }^{16}$ Hasta la misma asistencia de las mujeres como público era mal vista, y ni qué decir de sus intervenciones a finales del siglo XIX como actrices: Correa Serna, Nancy Yohana. Mujeres en escena. De Susana Tirado a Marina Ughetti, (tesis de maestría), Universidad Nacional de Colombia-sede Medellín, 2014.

${ }^{17}$ Bourdieu, Pierre. Campo de poder, campo intelectual (Tucumán: Montressor, 2002), p. 9.
} 
Si bien, en los años veinte en el campo literario se abrían paso algunas mujeres de la ciudad, el teatro siempre fue un terreno poco explorado en el campo intelectual local, pues la ausencia de un teatro nacional, de compañías locales y de escuelas de dramaturgia, no estimulaban este tipo de escritos. Sin embargo, en la primera mitad del siglo XX, se publicaron algunas obras de teatro, figuraron los dramaturgos Lino Ospina, Ciro Mendía, Salvador y Alejandro Mesa Nicholls, Julio Vives Guerra, José Luis Restrepo, Emilio Franco, Miguel Villa Uribe e Isabel Carrasquilla, y si bien ninguna de las obras de Ospina de Navarro fue editada, si se apreciaron algunas en los proscenios locales ${ }^{18}$.

En la historia del teatro colombiano, figuran pocas dramaturgas; en el siglo XIX solo se tiene noticia de tres escritoras, que se ocuparon en algunas ocasiones, de comedias. Josefa Acevedo de Gómez ${ }^{19}$, Waldina Dávila de Ponce de León ${ }^{20}$ y Soledad Acosta de Samper ${ }^{21}$, dejaron entre sus obras unas cuantas piezas teatrales. Contemporáneas a las dos dramaturgas al margen que analizamos, se encuentran Alicia Merizalde de Echavarría, la jericoana Dolly Mejía, y la barranquillera Amira de la Rosa. Con Paz Doméstica $^{22}$, una pieza de Merizalde, fue inaugurado el Teatro Bolívar de Medellín en 1919, y Dolly Mejía publicó su poema dramático Manos atadas ${ }^{23}$, en 1951. Por su parte, de la Rosa, que estudió en España periodismo y se especializó en teatro y en crítica teatral, se ocupó de casi todos los géneros (poesía, drama, comedia, radioteatro, novela, cuento, relato infantil, crónica periodística, crítica literaria, cinematográfica y artística), y puso en escena varias de sus obras, entre ellas, Madre borrada, Piltrafa, Las viudas de Zacarías y Los hijos de ella ${ }^{24}$. En Bogotá figuró Teresa Tanco de Herrera, quien escribió para voz piezas sacras, y en 1937, compuso la música para "Similia Similibus", una zarzuela histórica nacional, escrita en 1883 por Carlos Sanz Echavarría. Y aunque no precisamente se ocupó de comedias, Merceditas Escobar, la primera actriz y cantante de la Compañía Juvenil de Zarzuelas Frutos de la Montaña, creó diversos actos para amenizar las representaciones llevadas a cabo por la troupe ${ }^{25}$.

\footnotetext{
${ }^{18}$ Para mayor información sobre los teatros de Medellín de la primera década del siglo XX: Correa Serna, Nancy Yohana. "El Teatro Bolívar y otros espacios para las representaciones escénicas en Medellín, 18501950”, en Historia y espacio, núm. 17, Cali, Universidad del Valle, 2016, pp. 41-65.

${ }^{19}$ Según José Vicente Ortega y Ricaurte, Acevedo de Gómez publicó tres obras: En busca de almas, Mal de novios y La coqueta burlada. Ortega y Ricaurte, José Vicente. Historia crítica del teatro en Bogotá (Bogotá: Talleres de Ediciones Colombia, 1927), p. 185.

${ }^{20}$ Dávila de Ponce de León, Waldina. Zuma (Bogotá: Casa Editorial de J. J. Pérez, 1892).

${ }^{21}$ Soledad Acosta de Samper publicó tres dramas: El viajero, Las víctimas de la guerra y Las desdichas de Aurora. Reyes Posada, Carlos José. Teatro colombiano del siglo XIX (Bogotá: Imprenta Nacional, s.f.), p. 350.

${ }^{22}$ Correa Serna, Nancy Yohana, Op Cit., p. 52.

${ }^{23}$ Mejía, Dolly. Manos atadas (Bogotá: Kelly, 1951).

${ }^{24}$ Rosa, Amira de la. Amira de la Rosa. Obra reunida (I) Retalos, prosa, teatro (Bogotá: Maremagnum, 2005).

${ }^{25}$ Correa Serna, Nancy Yohana. "Compañías de teatro y trabajo infantil en Medellín. El caso de Merceditas Escobar en Frutos de la Montaña”, en Anuario de Historia Regional y de las Fronteras, vol. XXII, núm. 1, Bucaramanga, Universidad Industrial de Santander, 2017, pp. 89-112.
} 
Mujeres detrás de la escena: Isabel Carrasquilla y Sofia Ospina de Navarro, dramaturgas...

En este contexto, Isabel Carrasquilla y Sofía Ospina de Navarro escribieron sus comedias; dos dramaturgas al margen que coincidieron en espacios de sociabilidad, como la revista Letras y Encajes, y el Centro Femenino de Estudios, y de quienes se analizarán algunas de sus comedias, a fin de comprender las representaciones de género que pusieron en escena en el acontecer del Medellín de la primera mitad del siglo XX. La fuente principal consultada, fueron las obras de teatro de las escritoras, y algunas crónicas de la prensa y de revistas locales, las cuales, a través de la categoría de género, entendida como un "[...] elemento constitutivo de las relaciones sociales basadas en las diferencias percibidas entre los sexos y [como] una forma primaria de relaciones significantes de poder" 26 , y, de la historia cultural, la cual se podría circunscribir como la "[...] historia de las prácticas y las representaciones y pone su acento y su mayor atención en el estudio de las lógicas y las racionalidades, que se tejen en determinados grupos humanos" ${ }^{27}$, contribuyeron a ubicar a las dramaturgas como intelectuales y como partícipes de la escena cultural de la ciudad.

\section{Letras y Encajes: primera revista femenina de Medellín}

Sofía Ospina de Navarro fue directora de Letras y Encajes: Revista femenina al servicio de la cultura, junto con Ángela Villa de Toro, Alicia Merizalde de Echavarría y Teresa Santamaría. La revista que se fundó con el fin de acumular algunos fondos para contribuir con la construcción del Pabellón de Maternidad del Hospital San Vicente de Paúl, dejó claro desde su primera edición, que no ostentaría el "sello pretencioso de un órgano feminista"28; volcándose a ser abanderadas de los ideales conservadores en torno al mantenimiento de la concepción tradicional de la feminidad. Sin embargo, la investigadora Lola Luna afirma que, Letras y Encajes, contribuyó a la discusión nacional sobre los derechos de las mujeres, desde una perspectiva que recogía las opiniones conservadoras sobre la educación, el voto y el divorcio ${ }^{29}$, las cuales se habían elevado a la escena pública con mayor fuerza, tras la celebración del IV Congreso Internacional Femenino que se llevó a cabo en la ciudad de Bogotá y que coincidió con el ascenso al poder del Partido Liberal.

La revista contó con gran auge en sus más de veinticinco años de existencia; en 1941, por ejemplo, se publicaban mensualmente alrededor de 500 ejemplares para los ya tradicionales subscriptores. Según la directora de aquella época, “[...] desde sus columnas se ha[bían] librado importantes campañas a favor de la mujer, especialmente en la época de la Reforma del Código Civil y cuando el asunto del bachillerato" ${ }^{30}$.

\footnotetext{
${ }^{26}$ Scott, Joan. "El género: una categoría útil para el análisis histórico", en Lamas, Marta (comp.), El género: la construcción cultural de la diferencia sexual (México: PUEG, 1996), p. 23.

${ }^{27}$ Ceballos Gómez, Diana Luz. Prácticas, territorios y representaciones en Colombia, 1849-1960 (Medellín: Universidad Nacional de Colombia, 2009), p. 23.

28 “La dirección”, en Letras y Encajes, núm. 1, Medellín, Tipografía Industrial, 1926, p. 1.

${ }^{29}$ Luna, Lola. El sujeto sufragista, feminismo y feminidad en Colombia 1930-1957 (Cali: Universidad del Valle, 2004), pp. 92-93.

30 "Silueta de una gran dama antioqueña. Tomado de "La Razón” de Bogotá, en Letras y Encajes, núm. 174, Medellín, Tipografía Industrial, 1941, p. 5046.
} 
Las revistas femeninas en Colombia se inauguraron en 1880 con La Mujer, una publicación liderada por la escritora Soledad Acosta de Samper, que abonó el camino para las publicaciones de este tipo en el siglo XX, en el cual, junto con Letras y Encajes, se conocieron las siguientes: Catleya de Popayán; Manizales, dirigida por Blanca Isaza de Jaramillo, y Númen, ambas de Manizales; Acción Femenina de Tunja; Cristal y Mireya de Bogotá; Iberia de Barranquilla y Pétalos de Yarumal, Antioquia, entre otras.

Hasta el número veinte, que correspondió a marzo de 1928, Ospina de Navarro hizo parte del equipo editorial. Su renuncia no implicó que abandonara las columnas de la revista, en las cuales continuó publicando crónicas, cuentos y algunos dramas, hasta la fecha de su cierre, en septiembre de 1959. También, se conocieron sus escritos a través de las revistas: Vida: Revista de arte y literatura y Mireya, de Bogotá; y Sábado; Raza, Progreso -órgano de la Sociedad de Mejoras Públicas de Medellín-; Letras Universitarias, dirigida por la Facultad de Derecho de la Universidad de Antioquia; y El Bodegón: Revista de literatura y buen humor, de Medellín. Por otro lado, fue colaboradora habitual de los periódicos El Colombiano de Medellín y, El Espectador y El Tiempo, que circulaban en todo el territorio nacional.

En Letras y Encajes Sofía Ospina de Navarro publicó las siguientes crónicas, cuentos o charlas:

- "De luto", cuento que después se convertiría en la obra de teatro "Un luto pasajero". 1926.

- "En una boda. Cuento". 1926 y 1941.

- "Oyendo a un paisa". 1926.

- "Maldita selección”. 1927.

- "Prólogo de un drama". 1929.

- "Los tés elegantes". 1935.

- "Las señoras quieren carro". 1935.

- "La fe del carbonero". 1936.

- "Retazos de vida". 1938.

- "Milagro". 1940.

- "Dejad a los niños". 1941.

- "Detrás de las puertas". 1941.

- "Persiguiendo la línea". 1941.

- "El primer paso". 1941.

- "El favor de San Antonio". 1941.

- "La Madrina". 1941.

- "Cupido no vuela". 1942.

- "Un estreno memorable". 1942.

- "Delicias hogareñas". 1943.

- "Merceditas. Crónica". 1943.

- "Secretos comerciales". Cuento. 1943.

- "Debilidades femeninas". 1945.

- "Palabras pronunciadas en el homenaje a la primera dama, doña Carola Correa de Rojas Pinilla". Discurso. 1953. 
Mujeres detrás de la escena: Isabel Carrasquilla y Sofia Ospina de Navarro, dramaturgas...

Además, publicó como libros: Cuentos y crónicas (1926); La cartilla del hogar (1956); Don de gentes. Comprimidos de cultura social (1958); La abuela cuenta (1964, 2004) y La buena mesa (1933), que cuenta con 27 ediciones y que según afirmaba en una entrevista que le realizaron a su autora en 1974, año de su muerte, era, en aquella época, “[...] el libro más vendido de cuantos se han impreso en el país: [...] quince ediciones agotadas que han vendido 150.000 ejemplares, con las recetas clásicas de la comida criolla" ${ }^{\prime 3}$.

\section{Imagen 1. Foto tomada en el Club El Campestre de Medellín, con motivo de la publicación del libro Cuentos y crónicas de Sofía Ospina de Navarro. Aparece en el centro, Sofía Ospina de Navarro y alrededor algunas de sus amigas con copia del libro.}

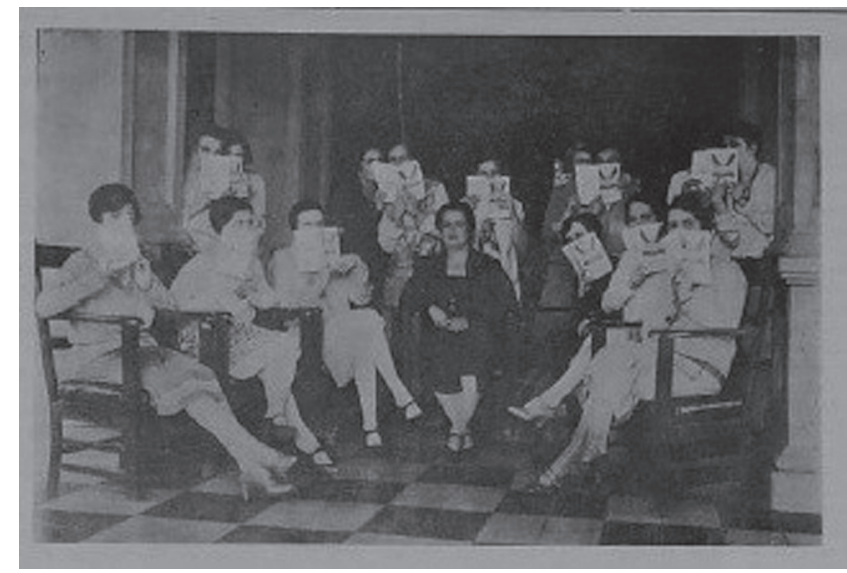

Fuente: Letras y Encajes, núm. 16, Medellín, Tipografía Industrial, 1927, p. 259.

Los temas recurrentes en los cuentos, las crónicas y las charlas de Ospina de Navarro fueron las relaciones familiares, en las cuales abogaba por el mantenimiento de la estructura tradicional de los hogares, que se mostraba amenazada por las trasformaciones sociales a las cuales se veía abocado el contexto local, por el crecimiento económico y demográfico que implicó el despegue de las actividades industriales. En este contexto, Ospina de Navarro da cuenta de su posición frente al sistema de relaciones sociales, una posición que respondió a su lugar de enunciación; una mujer de la élite económica, política y cultural de Medellín. Sus escritos son fiel reflejo de algunas prácticas culturales del sector económico al cual pertenecía, actividades que les permitían distinguirse del resto de la población; el trato con el servicio doméstico, los conocimientos de las reglas de urbanidad, de la ética y de la cultura, y las recetas, tan necesarias para las mujeres, para quienes, según la autora, "[...] entre los muchos deberes matrimoniales con que la mujer se encuentra enfrentada de buenas a primeras, ocupa lugar prominente el de la dirección de la comida"32, solo eran algunos de los aspectos que dan cuenta de su posición política.

\footnotetext{
${ }^{31}$ Tafur, Pilar. "Sofía Ospina de Navarro. Ocupación: Mujer", El Tiempo, Bogotá, 10 de mayo de 1974.

32 Ospina de Navarro, Sofía. La cartilla del hogar (Medellín: Editorial Carpel, 1956), p. 6.
} 
Su discurso estaba atravesado por los estereotipos de género, en el cual evidenciaba las tensiones en los mismos, a causa de los cambios sociales que ella percibía con la circulación que generaron las ideas liberales y feministas, de los cuales empezaban a apropiarse algunas mujeres; en su mayoría de los sectores obreros, ideas que se materializaron en el IV Congreso Internacional Femenino y en el proyecto de divorcio matrimonial presentado en 1935 en el Congreso de la República.

La gran aceptación y acogida de Sofía Ospina de Navarro en el campo intelectual local, se debió en parte, a su espíritu cívico, pues hizo parte del cuadro de honor de la Sociedad de Mejoras Públicas en varias ocasiones, y a su trabajo en favor de los más desamparados económicamente de la ciudad, a quienes apoyaba a través de obras de beneficencia, como el montaje de obras de teatro.

Por otro lado, de Isabel Carrasquilla, se publicaron en la revista entre 1938 y 1939, algunos de los apartados de sus impresiones de viaje, los cuales correspondieron a sus recuerdos de "Sevilla"; de las "Ruinas de Italia"; de las "Ruinas de Pompeya"; de "Florencia"; de "Venecia"; sus "Recuerdos de Nueva York" y "Una visita a la Alhambra". Es decir, salieron a luz pública a medida que la autora escribía su relato autobiográfico, el cual se publicó completamente en el año 2011 cuando Paloma Pérez Sastre los recuperó. Este es el tipo de escritora que Batticuore denomina como autoría póstuma y autoría intervenida, pues los textos fueron modificados para su mejor comprensión por la editora de los mismos. Aunque sus obras de teatro no fueron publicadas en Letras y Encajes, sus obras Filis y Sarito y Pepa Escandón, vieron la luz pública por la Tipografía Bedout que, en la tercera década del siglo XX, las puso en circulación en la ciudad.

\section{Centro de Estudios Femenino de Medellín. Un espacio para la sociabilidad}

El Centro de Estudios Femeninos inició labores el 13 de marzo de 1929 por iniciativa de la también directora de la revista de Letras y Encajes, Ángela Villa Toro; fue un espacio de sociabilidad donde se reunieron mujeres de la élite para reflexionar sobre asuntos que se consideraban de relevancia para la época. Tras seis años de funcionamiento contaban con 36 integrantes que se reunían semanalmente en un salón propio, para escucharse las unas a las otras, las exposiciones sobre temas de estudio de actualidad política, económica e intelectual. Las integrantes, que eran consideradas por Emilia Gutiérrez de Gutiérrez como "socias de la más alta categoría social, [y como...] mujeres inteligentes, entusiastas y preparadas" preparaban algunos temas para su exposición en plenaria; Ospina de Navarro, que habló en varias ocasiones, se refirió especialmente al "arreglo y servicio de la mesa y asuntos sociales" e Isabel, se refirió a asuntos pedagógicos. El centro se convirtió en un espacio de sociabilidad por excelencia de las mujeres de la elite económica local, en él compartieron valores, actitudes y formas simbólicas que rigieron ciertas

\footnotetext{
${ }^{33}$ Gutiérrez de Gutiérrez, Emilia. "La mujer antioqueña”, en Letras y Encajes, núm. 112, Medellín, Tipografía Industrial, 1935, pp. 1781-1783.
} 
Mujeres detrás de la escena: Isabel Carrasquilla y Sofia Ospina de Navarro, dramaturgas...

de sus conductas frente a los cambios sociales por los que atravesaba la ciudad con rapidez.

A mediados de 1940, tras terminar las labores del primer semestre de dicho año, se reunieron en casa de la presidenta del Centro de aquella época, Lía Jaramillo de Uribe, quien ofreció una recepción y encomendó a la socia Santamaría para que realizará el saludo de bienvenida, en el cual se resaltaron las labores llevadas a cabo en más de diez años de trabajo, pese a los rumores que se tejían en algunos círculos sociales de la ciudad. En dichos círculos, señalaban al centro de ser “[...] la reunión de unas tantas damas pedantes y marisabidillas que semanalmente se juntan con el ánimo de hablar de cosas y de hechos que apenas si entienden"34. Las socias, que defendían su asociación, afirmaban que el Centro había surgido

[...] de la necesidad que tiene la mujer actual, como parte integrante de la sociedad, de no permanecer al margen de los acontecimientos y mucho menos de ignorar las causas y los resultados más o menos malos o buenos de ellos. Hoy, en esta vida relámpago que llevamos, en que los descubrimientos científicos se suceden a los descubrimientos; en que las naciones cambian de dueño de la noche a la mañana, la mujer no puede, ni debe permanecer como antaño, hilando la rueca y trenzando sus largos cabellos. Los tiempos son otros y los hombres también ${ }^{35}$.

Y como querían estar enteradas de todo lo que sucedía a su alrededor y cultivar las bellas artes, la primera década del centro de estudios se conmemoró con la puesta en escena de una comedia de Sofía Ospina de Navarro en el Teatro de Bellas Artes. El acto se realizaba como muestra de la satisfacción que les generaba tener en sus filas a más de treinta integrantes y de haber incidido "[...] en el establecimiento del bachillerato femenino y en la aprobación de la reforma de código civil respecto a la mujer casada, asuntos ambos de gran trascendencia en la vida de la mujer" ${ }^{36}$. De la misma manera celebraron las bodas de plata, las cuales según anunciaron serían festejadas con la presentación de Un paso de comedia, de Ospina de Navarro, con un clásico pastel, con una copa de champan y con un discurso pronunciado por la fundadora del centro, Ángela Villa de Toro ${ }^{37}$.

\section{Representándose a ellas mismas. El Teatro de las dramaturgas al margen}

Los temas de las relaciones familiares, el amor y las transformaciones culturales que vivió Medellín en la década del treinta y el cuarenta, tratados por otros

\footnotetext{
${ }^{34}$ Santamaría de González, Teresa. "Nuevas socias del Centro Femenino de Estudios", en Letras y Encajes, núm. 168, Medellín, Tipografía Industrial, 1940, p. 4701.

35 Ibid., p. 4704.

${ }^{36}$ Santamaría de González, Teresa. "Décimo aniversario", en Letras y Encajes, núm. 152, Medellín, Tipografía Industrial, 1939, p. 3731.

${ }^{37}$ Santamaría de González, Teresa. "Centro Femenino de Estudios”, en Letras y Encajes, núm. 328, Medellín, Tipografía Industrial, 1953, p. 3320.
} 
dramaturgos, entre ellos Ciro Mendía, fueron captados desde una óptica femenina por Isabel Carrasquilla de Arango y Sofía Ospina de Navarro en sus comedias. Las escritoras junto con Alicia Merizalde de Echavarría y Dolly Mejía fueron las únicas dramaturgas con las que contó la ciudad en la primera mitad del siglo XX, y si bien, la mayoría de sus obras no se escenificaron en las tablas de los teatros de la ciudad, si se interpretaron en funciones privadas por actores aficionados que entretenían las veladas de los allegados a las autoras. Ellas escribieron en un momento en el cual las mujeres se habían labrado un espacio en la escena cultural internacional, como empresarias teatrales, actrices principales de gran factura y dramaturgas.

En 1933, Isabel escribió Comedias, una obra inédita con dos cuentos, un juguete cómico, un diálogo escolar y "tres dramas fuertemente influidos por el teatro de Jacinto Benavente" ${ }^{38}$. En los tres dramas incluidos en Comedias, las relaciones amorosas son el tema principal, debido a que "[...] las protagonistas ven coartados sus deseos por el autoritarismo de sus maridos, padres o hermanos, y cuentan con alguien de su mismo sexo que las ayuda en el cumplimiento de sus aspiraciones. [Así, la obra inédita] deja ver un afán educativo; por eso, resultan excepcionales tanto la temática, como la postura no moralizante de "Contra Viento y Marea", que reivindica el amor espontáneo y la independencia de las mujeres" 39 . La pieza dramática con mayor reconocimiento fue "Una Llanta Rota", premiada con la primera y única mención honorífica en los Juegos Florales de 1933. Dos años después fue llevada a las tablas del Teatro Bolívar por un grupo de artistas locales, entre ellos los reconocidos actores Celestino Riera, Clarisa Márquez de Riera y Amalia Gil, que no solo le rindieron un homenaje a su amiga Isabel dándole vida a los personajes de la pieza dramática, sino que también contribuyeron con una obra de caridad, pues el producido de la función se donó a la Casa de la Misericordia ${ }^{40}$. Según publicó la revista Letras y Encajes, “[...] los artistas que lo representaron estuvieron discretos y cada cual procuró meterse dentro del personaje que le correspondía, dejando a un lado el triunfo personal para dar paso al triunfo del conjunto y de la obra en general" ${ }^{41}$. En el momento en que Isabel reconoce ser la autora de la obra y promociona su exhibición en el Teatro, pasa de lo que Graciela Batticuore denomina autoría escondida, a una autoría apropiada y exhibida, en la cual su trabajo ha alcanzado cierto reconocimiento y aprobación de los círculos sociales e intelectuales de la época. El tránsito de una autoría escondida a una autoría exhibida, requirió de tiempo. Si bien, Ciro Mendía firmaba bajo su pseudónimo, su situación fue muy diferente a la de Isabel, pues él decidió darse a conocer de dicha manera, mientras que Isabel se vio forzada a esconder su identidad

\footnotetext{
${ }^{38}$ Pérez Sastre, Paloma. Isabel Carrasquilla de Arango, escritora y viajera, http://www.tragaluzeditores. com/isabel-carrasquilla-de-arango-escritora-y-viajera/, (20 de junio del 2017). Benavente fue uno de los dramaturgos españoles más vistos en la ciudad de Medellín, durante la época de estudio. Correa Serna, Nancy Yohana. "Obras de teatro y censura en Medellín entre 1850 y 1950", en HistoRelo. Revista de Historia Regional y Local, vol. IX, núm. 17, Medellín, Universidad Nacional de Colombia Sede Medellín, 2017, pp. 25-26.

${ }^{39}$ Ibid.

40 “Una llanta rota”, El Colombiano, Medellín, 14 de noviembre de 1935.

${ }^{41}$ Santamaría de González, Teresa. "Una llanta rota”, en Letras y Encajes, núm. 112, Medellín, Tipografía Industrial, 1935, p. 1798.
} 
Mujeres detrás de la escena: Isabel Carrasquilla y Sofia Ospina de Navarro, dramaturgas...

en sus primeras publicaciones, debido a las consecuencias personales que le podría acarrear la edición de sus textos por el hecho de ser mujer.

Tras la representación de "Una Llanta Rota", El Colombiano afirmó que la obra contemplaba una cantidad de elementos curiosos y sencillos de la vida medellinense, que juntos la convertían en la "[...] primera comedia que registre en Antioquia un estado espiritual y social de nuestro vivir serio y descontento" 42 . La escritora, el elenco y la calidad de la obra, garantizaron la asistencia de gran parte de la elite, que acudió a presenciar en escena las desventuras de una mujer engañada por su prometido. La pieza se divide en tres actos, que transcurren en la casa de la familia de Don Pablo y Doña Carmen, que viven junto con sus dos hijas Amparo, Rosario y la criada Zoila. Amparo se había educado en un internado, donde se convirtió en una mujer tranquila que no gustaba mucho de las diversiones mundanas, lo único que ocupaba su tiempo era su prometido Pedro, al cual consideraban su madre y hermana un buen partido, un caballero, bien nacido, educado y rico. Por su parte, su padre estaba convencido que el joven se inclinaba mucho por las diversiones y por las mujeres, razón por la cual le causaba melancolía entregar a su hija en el altar. Mientras Amparo soñaba con una vida plena de amor a lado de su enamorado, su hermana Rosario disfrutaba de practicar en el club deportes como el basquetbol y el tenis, no tenía novio, pero se sentía atraída por el Dr. Céspedes, el médico de la familia, un hombre muy simple y dedicado al trabajo, que visitaba la casa recurrentemente para velar por la salud del convaleciente Pablo tras haber sido atropellado por una motocicleta. En este acto, Pedro le informa a Amparo que saldría de viaje a la finca por unos días y Rosario la convence para que la acompañe a un paseo a la casa de las Robledo en Acevedo.

Las hermanas acuden a la invitación, pero por razones de salud de Amparo se ven en la necesidad de regresar a la casa en tren, ya que nadie en ese momento podría transportarlas hasta la ciudad. En el camino a la estación, avistaron dos autos estacionados al otro lado del puente y a unos hombres reponiendo una llanta; al acercarse a la escena pudieron comprobar que uno de los hombres era Pedro y que se encontraba con dos amigos y tres mujeres de esas, las cuales vociferaban palabras soeces mientras ellos intentaban esconderse. Fue tal su sorpresa que Amparo terminó por enfermarse aún más; en vista de la situación pasó un mes en el campo buscando reponerse del incidente y al cabo de dos meses estuvo lista para encontrarse de nuevo con Pedro, quien había solicitado a Pablo una entrevista con su hija. En el encuentro, Amparo ofrece su perdón, pero ratifica la ruptura del noviazgo, horas más tarde informa a su familia que en adelante su futuro estaba comprometido con las hermanitas de los pobres. A su vez, Rosario y el Dr. Céspedes convienen en iniciar una relación amorosa. Aunque las dos hermanas poseían personalidades diferentes, ambas soñaban con contraer matrimonio y conformar una familia, Amparo estaba dispuesta a amoldarse a los gustos y modo de vivir de su prometido, en tanto esas necesidades no la obligaran a descuidar sus deberes como cristiana. Rosario, pese a su gusto por las diversiones, aceptó la compañía de su pretendiente a sabiendas de lo conservador que se mostraba. Así, el matrimonio se presenta en la obra como el camino que debían

${ }^{42}$ E. G., "Del teatro y la pantalla. Una llanta rota”, El Colombiano, Medellín, 14 de noviembre de 1935. 
seguir las mujeres o en su defecto, unirse a comunidades religiosas para ayudar a los más desvalidos.

La segunda obra de Isabel Carrasquilla incluida en su tomo de Comedias, es "Contra viento y marea", una pieza "[...] ubicada en los años treinta, [que] sin precedentes refleja la irrupción de las ideas socialistas y feministas en el ámbito medellinense" La comedia en tres actos se desarrolla en la casa de Manuel, padre de María, Margarita y Ernesto. La madre y esposa había fallecido cuando Ernesto aún era un niño, razón por la cual sus hermanas asumieron su cuidado, sin pensar que en la adultez se convertiría en un hombre agresivo y maltratador. María estaba comprometida con su primo Carlos, relación que respondía a los deseos de su padre y hermano, pero no respondía al verdadero amor de ella, Raúl, un socialista líder del sindicato de obreros, que escribía artículos para la prensa y que se ocupaba de asuntos políticos. Carlos sabía del amor que su prometida sentía por el socialista, de modo que no la forzó para que lo amara, concediéndole tiempo y espacio con el fin de que olvidara su anterior amor.

María y su hermana Margarita, estudiante de enfermería, tenían una amiga llamada Ofelia, a quien según ellas "le había entrado lo del feminismo". Ofelia se encargó de servir de intermediaria entre Raúl y María. El socialista había comprendido que María aún lo amaba, pues esta decidió ponerle punto final al compromiso con Carlos y solicitarle apoyo a su hermana debido a que "estaba resuelta a todo con Raúl”, incluso a casarse por encima de la voluntad de su hermano y de su padre. Así, una mañana muy temprano Raúl recogió en casa a su amada María, antes de salir forcejeó con Ernesto, el cual se oponía a toda costa, pero este terminó derrotado y los enamorados se marcharon. Horas después, Margarita encontró una carta sobre la mesa, en ella María les comunicaba que viajaba con destino a Bogotá y que se casaría con Raúl. Su padre quedó desconsolado, afirmó que su hija le manchó sus canas, a lo que Margarita le respondió que se tranquilizara, que Raúl era un hombre libre, su hermana ya había alcanzado la mayoría de edad, que se iban a casar legítimamente y que esto era suficiente justificación para que aprobara la relación.

Los personajes femeninos de "Contra viento y marea" son muy diferentes a los retratados en la anterior obra; aunque la trama gira igualmente alrededor de una historia de amor, las mujeres demuestran más determinación para alcanzar su felicidad, pues toman sus propias decisiones y asumen las consecuencias de las mismas. Además, anteponen su voluntad a la autoridad del padre y del hermano, y desafían las pautas sociales al huir de su casa con un hombre sin previo matrimonio y sin consentimiento de su familia; sin refrendar el amor ante los ojos de Dios y del entorno social.

La protagonista de la tercera pieza dramática, no contó con la suerte de María, pues como el nombre de la comedia lo indica "Ida y Vuelta", ella se fue con las ilusiones de ser feliz y regresó desengañada del amor. La obra se desarrolla en dos actos, el

\footnotetext{
${ }^{43}$ Pérez Sastre, Paloma. Isabel Carrasquilla de Arango, escritora y viajera, http://www.tragaluzeditores. com/isabel-carrasquilla-de-arango-escritora-y-viajera/ (20 de junio del 2017).
} 
primero en un cuarto de hotel y el segundo en el costurero de una casa de bajos recursos económicos. En esta como en las anteriores piezas, la protagonista es una mujer joven de la élite local. Ella se enamoró de Aníbal, un bogotano que llegó a Medellín para correr en el hipódromo como jockey y que, además, según le afirmó a su familia, se desempeñaba como agente de petróleos en toda Colombia y en el extranjero. Celia no pudo resistir la atracción que sentía por Aníbal, tanto que durante la temporada que este corrió en el hipódromo, ella se aficionó a las carreras, además obvió los consejos de su familia al advertirle que el hombre era jugador, bebedor y enamoradizo. El joven bogotano aprovechando que se había ganado el amor de Celia, pidió su mano cuatro meses después de haberla conocido.

Tras el matrimonio la pareja se mudó a la capital, Celia empacó todo lo necesario para su nueva vida, incluyendo los regalos que les habían obsequiado en la ceremonia de bodas. En el camino se hospedaron en un hotel de Puerto Berrío, donde esperaban que zarpara el barco que los llevaría más cerca de su destino final. Allí empezó a derrumbarse la mentira de Aníbal, quien fue reconocido por algunos trabajadores del hotel cuando este denunció el robo de un dinero de su esposa, que él mismo había tomado. Los camareros aseguraron que cuatro meses atrás, Aníbal junto con un amigo, se marchó si cancelar los servicios prestados en la posada. Los recién casados fueron expulsados del establecimiento y poco a poco Celia veía que las promesas de vivir en una elegante casa, se esfumaban como el amor de su esposo.

En el segundo acto aparece Celia en casa de Aníbal, en donde trabajaba como costurera para poder sobrevivir con su suegra, sus cuñadas y los hijos de éstas últimas. Aníbal se encargó de dejarla sin ninguna pertenencia y la obligó a mentirle a su familia sobre la situación en la que se hallaba. Celia pasó de hacer parte de la élite local medellinense a llevar una vida miserable, en la que su único consuelo fue el apoyo de la hermana de Aníbal, quien la motivaba constantemente para que informara a sus allegados sobre el fracaso del matrimonio. Cuando todo parecía empeorar, porque Celia se sentía cada vez más enferma, tomó valor y con la ayuda de su cuñada y de la señora para quien trabajaba, contactó a algunos familiares que residían en Bogotá con el fin de poder escapar, fuga que realizó una vez confrontó a su esposo para decirle lo mucho que lo aborrecía. Cuando se marchó, ella estaba embarazada de Aníbal. El personaje de Celia es aún más interesante, pues muestra la capacidad de las mujeres para defenderse económicamente por sí mismas, tal como lo evidenció la protagonista al dedicarse a la costura, y, además, denota el valor, pues se marchó de la casa de su esposo pese a saber que se encontraba en estado de embarazo, lo que implicaría convertirse en una madre separada. Aunque no se tiene noticia de la fecha de la obra, esta evidencia mostró un cambio trascendental en la concepción que poseía la autora sobre el matrimonio, quien, en 1935, no aparece como firmante en una protesta que las damas de Medellín escribieron en contra del proyecto de divorcio que se gestaba para la reforma constitucional del siguiente año ${ }^{44}$, protesta que estuvo encabezada por su homóloga Ospina de Navarro.

\footnotetext{
44 "Protesta. Las damas de Medellín protestan contra el proyecto de divorcio", en Letras y Encajes, núm. 109, Medellín, Tipografía Industrial, 1935, pp. 1699-1700.
} 
Otras obras de Isabel Carrasquilla que se llevaron a escena fueron "Pepa Escandón", representada en 1933 por la Compañía de Comedias Cómicas de Vidal Montoya y "Noche de Reyes", llevada a las tablas en 1936 por el Grupo Escénico de la Acción Social, dirigido por Ramón Soler Maymo. Como se mencionó anteriormente, "Pepa Escandón" fue una comedia basada en la novela Frutos de mi tierra, de Tomás Carrasquilla, la cual no sería la única obra llevada a escena del escritor antioqueño, pues varias compañías de teatro nacionales de la segunda mitad del siglo XX, inmortalizaron su obra En la diestra de Dios Padre con una adaptación para el teatro realizada por el dramaturgo caleño Enrique Buenaventura y el cuento El padre Casafús.

Imagen 2. Publicidad de la Compañía Cómica Vidal Montoya en 1933.

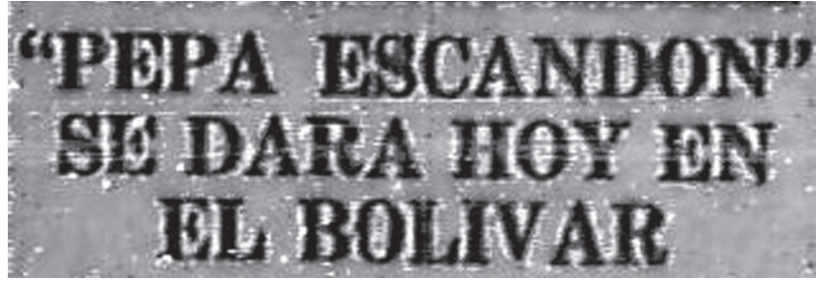

Fuente: El Colombiano, Medellín, 27 de junio de 1933.

Por su parte, Sofía Ospina de Navarro además de ser la primera antioqueña que publicó con éxito en Medellín cuentos y crónicas, también incursionó en la dramaturgia con obras como "Ascendiendo", "Un luto pasajero", "La familia Morales" y "Una junta benéfica”, las cuales, según la investigadora Mary G. Berg:

[...] son comedias de costumbres [...] que revelan tensiones sociales inherentes a las épocas de transición. [...] Describen un mundo tradicional de una ciudad pequeña algo aislada, en la cual ocurren recientes y asombrosas transformaciones promovidas desde el interior mismo de ese mundo y desde el exterior. Las cuatro obras dramatizan las vidas de cuatro mujeres, sus nuevas libertades y las tensiones y dudas que estas nuevas posibilidades conllevan ${ }^{45}$.

Las comedias se asemejan a las prosas costumbristas que Sofía escribía para la prensa y que publicó en su colección de relatos de Cuentos y Crónicas (1926). "Un luto pasajero" es una adaptación para las tablas de su artículo "De luto", publicado en el número uno de la revista Letras y Encajes. Así mismo, "Ascendiendo" era un cuento adaptado para el teatro, para ser representado en beneficio de la Cruz Roja.

Sofía Ospina, como se ha dicho ya, nació en Medellín en 1892, sus padres fueron Tulio Ospina Vásquez, hijo del expresidente Mariano Ospina Rodríguez, y Ana Rosa Pérez de Ospina, ambos pertenecían a familias de la élite económica medellinense. Cursó

\footnotetext{
${ }^{45}$ Berg, Mary G. "El teatro de Sofía Ospina de Navarro", en Lingüística y Literatura, núm. 61, Medellín, Universidad de Antioquia, 2012, p. 30.
} 
estudios en el Colegio de la Enseñanza y contrajo matrimonio con Salvador Navarro, con quien tuvo seis hijos. Protagonizando una notoria ruptura con las convenciones sociales de su época que le fue facilitada por su prestante familia, Sofía aparte de escribir cuentos y crónicas, fue colaboradora de los periódicos El Colombiano, El Espectador y El Tiempo por varios años, así como de la Revista Sábado, y de otras. Además, fue la primera concejala de Medellín, tiempo después de que las mujeres obtuvieron el derecho al voto, integrante y presidenta de la Sociedad de Mejoras Públicas, presidenta de la institución Ciudadanas de los Estados Unidos, perteneciente a la Sociedad Benéfica Santa Ana y fundadora de las Residencias Universitarias de Medellín ${ }^{46}$. En opinión de la investigadora Mary Berg, la escritora fue "[...] una persona de energía extraordinaria en cuanto a su organización, su compasión, y su cariño, pues se dedicó a recaudar fondos para obras de caridad y, a lo largo de su vida, promovió causas que adelantaron la educación y la salud de las mujeres"47.

El primer cuento que publicó se llamó "Milagro", lo escribió para uno de los nacientes concursos literarios de mujeres, en el cual obtuvo el segundo lugar. La familia de Sofía no se enteró de su participación en el certamen hasta la premiación; en posteriores declaraciones reconoció que su esposo casi se desmayó con la noticia y que gran parte del público supuso que la obra había sido escrita por su padre ${ }^{48}$, quien para entonces era un reconocido escritor y miembro de los círculos literarios de la ciudad, pues no podían concebir que un relato de tan buena factura y tema fuera obra de una mujer. En adelante continuó escribiendo estimulada por su padre y encontrando en la actividad un inesperado placer.

Una de sus comedias más importantes fue "La familia Morales", cuya primera representación se efectuó en Santa Fe de Antioquia y fue estrenada en Medellín en 1943, por la Compañía de Dramas y Comedias de la famosa actriz mexicana Virginia Fábregas. La pieza recrea los avatares de una familia que se muda del campo a Medellín porque la esposa, que había nacido en la ciudad, quería que su hija tuviera más posibilidades ${ }^{49}$. Tras la representación, Ospina de Navarro quedó tan sorprendida, que aseguró en una entrevista lo siguiente: "Doña Virginia la presentó con amor, no a mí sino a Antioquia. Descubrí cosas que yo no conocía en mi cuento. Porque hubo detalles tan preciosos, tan encantadores y sobretodo tan indispensables, que no vacilo en decirle que doña Virginia hizo una nueva familia Morales" ${ }^{50}$. Para la prensa el contenido de la obra retrataba el cambio de costumbres en una familia pueblerina que se trasladaba a Medellín y que más tarde -muerto el jefe del hogar, quien ejercía de guardián celoso de la vida sencilla- hace un viaje a París. Los cambios acontecidos en la vida familiar de los Morales, según la crítica local, subrayaban la idea de que la moral ya no se conducía de manera estricta sino relajada y mundana ${ }^{51}$. "La familia

\footnotetext{
${ }^{46}$ Melo, Livia Stella. Valores femeninos de Colombia (Bogotá: Carvajal, 1957), pp. 480-481.

${ }^{47}$ Berg, Mary G. "El teatro de Sofía Ospina de Navarro", p. 28.

48 "Doña Sofía Ospina de Navarro escribirá la biografía", p. 3.

${ }^{49}$ Berg, Mary G. "El teatro de Sofía Ospina de Navarro", p. 32.

50 "Doña Sofía Ospina de Navarro escribirá la biografía", p. 3.

${ }^{51}$ Ibid., p. 3.
} 
Morales" estaba compuesta por Agapito, el señor de la casa, un viejo apegado a sus tradiciones, su esposa Julia, quien gustaba de aparentar y la hija de ambos, Aura, que practicaba deportes como el basquetbol en el club y se codeaba con lo más granado de la sociedad medellinense, de quienes había aprendido nuevas costumbres que deseaba implementar en su casa, tales como el horario para cenar, el uso del briqué para que su padre encendiera los cigarrillos y una alimentación basada en frutas y verduras con el fin de mantenerse saludables.

Ambas mujeres soñaban con viajar a Europa, o cuando menos a Panamá, pues era fundamental para exhibir su nuevo estatus. Las dos deseaban tener todas las nuevas comodidades urbanas que la industria de los electrodomésticos ofrecía a las mujeres modernas para su hogar: nevera, agua caliente y cuarto de baño, comodidades necesarias para vivir como gente de verdad, pero que al parecer del padre, eran tontas modas de la ciudad. Los sueños de Aura se estaban haciendo realidad con la complicidad de su madre, quien le permitía verse a escondidas de su padre con su novio Luis Carlos. Este poseía un carro y era aficionado a las carreras de caballos; en alguna ocasión invitó a toda la familia al hipódromo, convite que Agapito rechazó por estar acostumbrado a movilizarse en mula. En el segundo acto, Julia y Aura tras la muerte inesperada de Agapito cuando iba camino a la tertulia de Don Luis, recibieron un telegrama de la Compañía Colombiana de Seguros en el cual les notificaban que eran acreedoras a diez millones de pesos correspondientes a una póliza que había adquirido el fallecido. Las mujeres decidieron invertir este dinero en realizar el soñado viaje a Europa en compañía de Luis Carlos, con quien Aura contrajo matrimonio y tuvo un hijo en París.

Imagen 3. Publicidad de la Compañía de Virginia Fábregas en 1943

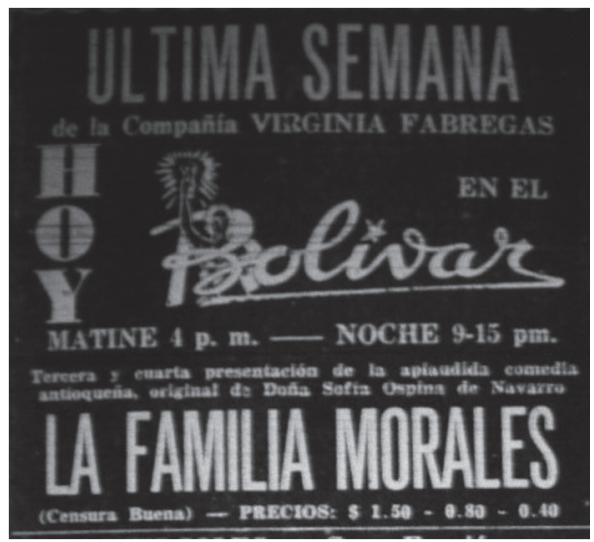

Fuente: El Colombiano, Medellín, 11 de julio de 1943.

Dos años después regresaron a Medellín convertidas en "todas unas damas parisenses", pues ya no se acomodaban a la alimentación local, habían traído una niñera francesa para que se ocupara del bebé, el cual sería hijo único porque en Francia no se usaban las familias numerosas, y estaban negociando la compra de una nueva vivienda en un barrio mejor ubicado y con mayores comodidades. En este momento, de acuerdo con 
Berg, “[...] sus preferencias por todo lo europeo parecen ridículas y casi patéticas en Medellín, pero ellas ni siquiera lo notan" ${ }^{52}$. Las amigas de Aura se percataron de la poca importancia que esta prestaba a su esposo, quien permanecía marginado de los negocios que ella realizaba, por esta razón aseguraban que "El feminismo está en toda su fina. Se acabó aquello de entregar al marido Cuerpo, Alma y Plata", pues la mujer disponía de sus bienes y podía negociar sin dar explicaciones, asunto que solo se trata en esta comedia, a diferencia de las demás obras de Ospina de Navarro, en las que las mujeres esperaban depender en todos los aspectos de sus esposos y de manera especial en el aspecto económico y material.

Finalmente, Aura se separó de Luis Carlos y recibió propuestas de un francés que había conocido durante el viaje de regreso al país. En definitiva, esta se mostraba como una mujer capaz de ser independiente, pues hacía uso de las nuevas posibilidades legales y logró transgredir las tradiciones y los límites culturales.

\section{Conclusiones}

No es una contradicción postular a dos mujeres de la elite económica y cultural de la capital de Antioquia como dos mujeres al margen. Su destacada posición social les permitió intervenir, tal vez de modos indirectos, en una escena pública dominada por esquemas masculinos, en parte como un legado de ese poder letrado del siglo XIX. Sus intervenciones son veladas, poco visibles en apariencia; todas dos asumen que su labor de escritura no es importante, que son una especie de amateurs. Ambas se enfrentaron a la transformación de las relaciones sociales tradicionales, pues hicieron parte de una generación que sintió los efectos de los acelerados cambios económicos de Medellín. No es de extrañar, por lo tanto, que intentaran retratar en sus obras de teatro unos niveles de angustia o desazón por los tiempos perdidos. Hicieron parte de experiencias fundamentales para la historia de las representaciones de género en Colombia, y en ese sentido muestran las ambigüedades y las tensiones de cualquier sujeto y campo intelectual: sus obras siempre estuvieron ligadas a las intervenciones del espíritu caritativo, era necesario anteponer, en la mayoría de ocasiones, el prominente rol doméstico que parecía ser natural al género femenino; no obstante, en sus ejercicios de ficción puede observarse la capacidad de romper con ciertos esquemas.

Ese rompimiento de esquemas se evidencia en la renegociación constante de los estereotipos y del orden de género, que se teje en las obras de teatro, en las cuales se construyó, de una forma diferente a la tradicional, la diferencia sexual. Si bien, para los personajes femeninos el único horizonte posible era contraer matrimonio, las dramaturgas al margen transgredieron la jerarquía de la diferencia sexual imperante, al darles agencia para tomar decisiones sobre sus vidas, y así contribuir en la transformación social de la forma en que se concebía la manera de ser y de actuar de

\footnotetext{
${ }_{52}$ Berg, Mary G. "El teatro de Sofía Ospina de Navarro", p. 33.
} 
las mujeres. Esas pequeñas rebeliones emprendidas por las protagonistas, en el caso de Celia de "Ida y vuelta", separarse de su esposo; o de María de "Contra viento y marea", que huye de su casa para contraer matrimonio con un hombre socialista, o de Aura de "La familia Morales", que decidía sobre sus bienes, fueron introduciendo en la sociedad medellinense nuevas pautas de comportamiento y de relacionamiento social. De esta manera, las obras se constituyen como un caso paradigmático para la historia de la ciudad, e incluso del país, pues a diferencia de las demás comedias de los dramaturgos locales, estas autoras visibilizaron desde las tablas, las búsquedas y las necesidades de las mujeres, una iniciativa que consciente o inconscientemente se sumaba a las acciones que ya se venían emprendiendo desde la revista Letras y encajes y desde el Centro Femenino de Estudios de Medellín.

De modo que la amenaza al orden de género establecido, encarnada en las protagonistas de las obras de teatro, fue uno de los tantos enunciados que se configuraron en favor de las mujeres, en asuntos tan importantes como el establecimiento del bachillerato femenino y la transformación del Código Civil respecto a la mujer casada, entre otros. Tanto así que Sofía Ospina de Navarro se convirtió en la primera mujer concejal de la ciudad de Medellín, y desde la revista Letras y encajes, se lideró la apertura y el funcionamiento del Colegio Mayor de la Cultura Femenina de Antioquia en la década de 1940. En tal sentido, puede pensarse que las preocupaciones del Centro Femenino de Estudios de Medellín y de la revista, trascendieron las fronteras de un pequeño círculo de mujeres de la elite económica local, pues estas incidieron políticamente en cambios que favorecieron en mayor o en menor medida, a las mujeres de otras clases sociales. Así mismo, la participación constante en obras de beneficencia, tales como el móvil de la fundación de la revista, que fue acumular algunos fondos para contribuir con la construcción del Pabellón de Maternidad del Hospital San Vicente de Paúl, dejan entrever las afinidades, los alcances y las preocupaciones generales de estas mujeres. Aunque en la mayoría de las ocasiones se puede observar la necesidad de abogar por el mantenimiento de la estructura tradicional de los hogares, estas mujeres detrás de las escena, comprendieron la importancia de que las mujeres pudieran avanzar en otros ámbitos, y de hecho así lo plasmaron en sus representaciones teatrales, formato textual al que debe volver con más asiduidad la historiografía para el análisis de los procesos intelectuales y de las transformaciones en las relaciones de género durante el siglo $\mathrm{XX}$.

\section{Fuentes}

\section{Fuentes primarias}

\section{Prensa}

El Colombiano, Medellín, 1912-1954.

El Tiempo, Bogotá, 10 de mayo de 1974. 
Mujeres detrás de la escena: Isabel Carrasquilla y Sofia Ospina de Navarro, dramaturgas...

\section{Revistas}

Letras y Encajes, Medellín, 1926-1956.

Mireya: Revista Femenina, Bogotá, 1943-1945.

\section{Obras de teatro inéditas}

Carrasquilla, Isabel. "Ida y vuelta". Comedia en dos actos. Teatro inédito.

Carrasquilla, Isabel. "Noche de reyes". Juguete cómico en un acto. Teatro inédito.

Carrasquilla, Isabel. "Una llanta rota”. Comedia en tres actos. Teatro inédito.

Ospina de Navarro, Sofía. "La familia Morales". Teatro inédito.

Ospina de Navarro, Sofía. "Un luto pasajero". Teatro inédito.

\section{Fuentes secundarias}

\section{Libros}

Batticuore, Graciela. La mujer romántica. Lectoras, autoras y escritores en la Argentina: 1830-1870. Buenos Aires: Edhasa, 2005.

Bourdieu, Pierre. Campo de poder, campo intelectual. Tucumán: Montressor, 2002.

Carrasquilla, Isabel. Impresiones de viaje. Medellín: EAFIT, 2011.

Carrasquilla, Isabel. Filis y sarito. Medellín: Bedout, 1932.

Carrasquilla, Isabel. Pepa Escandón. Medellín: Bedout, 1932.

Ceballos Gómez, Diana Luz. Prácticas, territorios y representaciones en Colombia, 1849-1960. Medellín: Universidad Nacional de Colombia, 2009.

Dávila de Ponce de León, Waldina. Zuma. Bogotá: Casa Editorial de J. J. Pérez, 1892.

De la Rosa, Amira. Amira de la Rosa. Obra reunida (I) Retalos, prosa, teatro. Bogotá: Maremagnum, 2005.

Lamus Obregón, Marina. Geografías del teatro en América Latina. Un relato histórico. Bogotá: Luna Libros Ltda, 2010.

Loaiza Cano, Gilberto. Poder Letrado: ensayos sobre historia intelectual de Colombia, siglos XIX y XX. Cali: Universidad del Valle, 2014. 
Luna, lola. El sujeto sufragista, feminismo y feminidad en Colombia 1930-1957. Cali: Universidad del Valle, 2004.

Melo, Livia Stella. Valores femeninos de Colombia. Bogotá: Carvajal, 1957.

Mejía, Dolly. Manos atadas. Bogotá: Kelly, 1951.

Ospina de Navarro, Sofía. La abuela cuenta. Medellín: Gran América, 1964.

Ospina de Navarro, Sofía. Cuentos y crónicas. Medellín: Tipografía Industrial, 1926.

Ospina de Navarro, Sofía. La buena mesa: sencillo y práctico. Medellín: Gran América, 1982.

Ospina de Navarro, Sofía. La cartilla del hogar. Medellín: Editorial Carpel, 1956.

Ortega y Ricaurte, José Vicente. Historia crítica del teatro en Bogotá. Bogotá: Talleres de Ediciones Colombia, 1927.

Zemon Davis, Natalie. Mujeres de los márgenes. Tres vidas del siglo XVII. Madrid: Ediciones Cátedra, 1999.

\section{Capítulos de libros}

Acosta de Samper, Soledad. "El viajero", en Reyes, Carlos José (comp.), en Teatro Colombiano siglo XIX. Bogotá: Imprenta Nacional, 2002.

Carrasquilla, Isabel. "Contra viento y marea", en Restrepo David, Felipe (com.), Dramaturgia antioqueña, 1879-1963. Antología. Medellín: EAFIT, 2014.

Loaiza Cano, Gilberto. "Entre la historia intelectual y la historia cultural, una ambigüedad fecunda", en Hering, Max (ed.), Historia Cultural desde Colombia. Categorías y debates. Bogotá: Universidad Nacional de Colombia, 2012.

Löwy, Michael. "El concepto de afinidad electiva en Max Weber", en Aronson, Perla (ed.), La vigencia del pensamiento de Max Weber a cien años de "La ética protestante y el espíritu del capitalismo. Buenos Aires: Gorla, 2007.

Pérez Sastre, Paloma. "Edición comentada de las Impresiones de viaje de una abuela para sus nietos de Isabel Carrasquilla de Arango", en Guardia, Sara (ed.), Viajeras entre dos Mundos. Lima: Centro de Estudios la Mujer en la Historia de América Latina CEHMAL, 2011.

Scott, Joan. "El género: una categoría útil para el análisis histórico", en Lamas, Marta (com.), El género: la construcción cultural de la diferencia sexual. México: PUEG, 1996. 
Mujeres detrás de la escena: Isabel Carrasquilla y Sofia Ospina de Navarro, dramaturgas...

\section{Artículos de revista}

Berg, Mary G. "El teatro de Sofía Ospina de Navarro", en Lingüística y Literatura, núm. 61, 2012, pp. 27-36.

Correa Serna, Nancy Yohana. "Compañías de teatro y trabajo infantil en Medellín. El caso de Merceditas Escobar en Frutos de la Montaña”, en Anuario de Historia Regional y de las Fronteras, vol. XXII, núm. 1, 2017, pp. 89-112.

Correa Serna, Nancy Yohana. "El Teatro Bolívar y otros espacios para las representaciones escénicas en Medellín, 1850-1950”, en Historia y espacio, núm. 17, 2016, pp. 41-65.

Correa Serna, Nancy Yohana. "Obras de teatro y censura en Medellín entre 1850 y 1950”, en HistoRelo. Revista de Historia Regional y Local, vol. IX, núm. 17, 2017, pp. 16-48.

Ospina de Navarro, Sofía. "Al calor de la lumbre", en Vida: Revista de Arte y Literatura, vol. I, núm. 5, 1936, pp. 5-6.

Ospina De Navarro, Sofía. "La Beata”, en Progreso, núm. 4, 1951, pp. 31-32.

Ospina De Navarro, Sofía. "La casa antioqueña”, en Progreso, núm. 1, 1948, pp. 2527.

Ospina De Navarro, Sofía. "Los amores de Marta”, en Sábado, vol. V, núm. 112, 1929, pp. 1495-1496.

Ramírez Patiño, Sandra Patricia. “Cuando Antioquia se volvió Medellín, 1905-1950. Los perfiles de la inmigración pueblerina hacía Medellín”, en Anuario Colombiano de Historia Social y de la Cultura, vol. XXXVIII, núm. 2, 2011, pp. 217-253.

\section{Tesis}

Correa Serna, Nancy Yohana. Mujeres en escena. De Susana Tirado a Marina Ughetti, (tesis de maestría), Universidad Nacional de Colombia, sede Medellín, 2014.

\section{Publicaciones en Internet}

Pérez Sastre, Paloma. Isabel Carrasquilla de Arango, escritora y viajera, http://www. tragaluzeditores.com/isabel-carrasquilla-de-arango-escritora-y-viajera/. 